\title{
Artificial Intelligence in the Law Firm of the Future
}

\author{
Gabriela Bar
}

\section{Introduction}

The future belongs to the rapidly evolving technology, and the most fascinating and capable of revolutionising any industry is Artificial Intelligence (AI). This technology will also be the main driver of changes in the legal profession. Today, many law firms are still trying to resist changes or wait them out, but soon clients of the law firm will not need, but also will not want, lawyers to work in the way they worked in the 20th or even at the beginning of the 21st century ${ }^{1}$. Traditional law firms will soon disappear from the market, just like video cassette rentals.

We can already talk about advanced automation of many activities. LegalTech tools can replace lawyers in performing routine and repetitive activities (e-discovery, document analysis and generation, due diligence, document management, task inventory, working time and invoicing). Recommendation systems that use predictive analytics will gain an importance and in the near future also advanced systems that take partially or fully autonomous actions that can cooperate with human lawyers will be more and more popular.

The role and way the lawyers work will change dramatically also because the knowledge of the applicable law will be more often "embedded" in various types of devices (e.g. autonomous vehicles, intelligent buildings, computers) and a user will not be allowed performing any activity inconsistent with legal or ethical requirements ${ }^{2}$. Thanks to the distributed ledger technology (DLT) and the wider use of the so-called smart contracts we will not need lawyers to draft many types of contracts and supervise their execution or help with their enforcement ${ }^{3}$.

Jurisprudence may decide about the need for a wider use of AI-based solutions in the lawyers work. Already in February 2012 the United States

1 Richard Susskind, Tomorrow's Lawyers. An Introduction to Your Future (Oxford University Press 2nd edn, 2017).

2 ibid, 73.

3 On this subject: Dariusz Szostek, Blockchain and the Law (1 ed., Nomos 2019). 
District Court (S.D. New York) in the case of Da Silva Moore v Publicis Groupe $^{4}$ found that computer-aided review of large amounts of documents and data has advantages over traditional methods (and is more beneficial to the client). In late 2018, the Ontario Superior Court of Justice ruled to reduce the party's claim for trial costs by $\$ 11,400$ (including questioning in full the amount of lawyers' fees for analysing data and documents in the case, calculated on the basis of hourly rates), accusing the party's attorneys of not using LegalTech tools, including AI, to conduct legal research, which unnecessarily overstated the costs of legal assistance ${ }^{5}$. The court found that lawyers should use algorithmic solutions, including AI, to shorten the preparation time for the trial. It seems that we will soon function in a reality in which failure to use LegalTech tools may constitute an improper performance of the legal service, and thus - not only civil liability, but also disciplinary liability of the lawyer. Therefore, lawyers of the future should be aware of the possibilities of $\mathrm{AI}$ and each time take into account the need to use it in their cases ${ }^{6}$.

The precursors of the implementation of AI systems are and will probably remain large international law and consulting companies, which are able to bear the high costs of designing dedicated solutions or purchasing ready-made software and integrating it with their own systems ${ }^{7}$. The pioneers group also includes modern domestic law firms operating in the technology industry (with flexible, innovative customer-oriented approach and need of cost reduction) and the so-called boutique law firms specializing in a narrow field of law (e.g. intellectual and industrial property, pharmaceutical law), for which the implementation of modern solutions based on AI means the possibility of significantly expanding the volume of cases without expanding the law firm itself and increasing employment.

4 The full text of the judgment is available at: <scholar.google.com/scholar_case?ca se $=6856971937505165396 \& \mathrm{q}=\mathrm{da}+$ silva + moore $+\mathrm{v} .+$ publicis + groupe\&hl=en\&as_s $\mathrm{dt}=40000006 \&$ as_vis=1> accessed: 11 January 2021. See also: Maura .R. Grosman, Gordon V. Cormack, 'Inconsistent Responsiveness Determination in Document Review: Difference of Opinion or Human Error' (2012) 32 Pace L. Rev., $267 \mathrm{ff}$.

5 The text of the judgment is available on the website of the Canadian Legal Information Institute, <www.canlii.org/en/on/onsc/doc/2018/2018onsc6959/2018onsc6959.h tml> accessed 6 January 2021.

6 Robert Ambrogi, 'Judge Penalizes Lawyers For Not Using Artificial Intelligence'. $<$ abovethelaw.com/2019/01/judge-penalizes-lawyers-for-not-using-artificial-intelligence/>, accessed: 13 January 2021.

7 John Armour, Richard Parnham and Mari Sako, 'Augmented Lawyering' (2020) 558 European Corporate Governance Institute - Law Working Paper. 


\section{Robo-assistant: Support for the Lawyers and Client Advisor}

Artificial Intelligence, which - thanks to deep learning - is making remarkable progress in recognizing images and understanding natural language, will undoubtedly replace - in the foreseeable future - younger lawyers who perform assistant and support functions in law firms ${ }^{8}$. It will replace them not only in the way we know today (due diligence, verification of standard contracts or contract templates, data analysis, automatic document creation, establishing the jurisprudence in a given category of cases), but will become a virtual assistant of an legal advisor attorney with specialist knowledge and the ability to communicate also with a law firm's clients. The tasks of robo-assistants will also include activities related to office management, such as answering phone calls, arranging meetings, keeping a calendar of courts hearings, managing incoming and outgoing correspondence, settling customers and handling procurement.

Advanced Legal Expert Systems (LES) - using machine learning algorithms, which offer the best solutions for a given problem, helping to make a final decision by a human lawyer - in the near future ${ }^{9}$ will communicate with users in natural language, explain the legitimacy of the proposed solution, answer the questions asked, and modify their recommendations after discussing the matter with a human. Today already, at least some of these competences are possessed by Watson IBM - it understands a legal problem presented in a natural language, is able to analyse and classify the information and then draw conclusions and provide legal advice, also presenting it in a computer simulated "human" voice ${ }^{10}$.

8 Dan Mangan, 'Lawyers could be the next profession to be replaced by computers' (CNBC 13 February 2017) <www.cnbc.com/2017/02/17/lawyers-could-be-repl aced-by-artificial-intelligence.html $>$ accessed 20 January 2021. See also: Carl Benedikt Frey, Michael A. Osborne, The Future Of Employment: How Susceptible Are Jobs To Computerisation?, <oxfordmartin.ox.ac.uk/publications/the-futureof-employment/>, accessed: 20 January 2021; <willrobotstakemyjob.com/23-2011 -paralegals-and-legal-assistants $>$, accessed 20 January 2021.

9 Jordan Furlong, The evolution of the legal services market, <law21.ca/2012/11/the-ev olution-of-the-legal-services-market-stage-1/>, <law21.ca/2012/11/the-evolution-of -the-legal-services-market-stage-2/> accessed: 13 March 2021., <law21.ca/2012/11/ the-evolution-of-the-legal-services-market-stage-3/>, accessed: 13 March 2021. See also: Kai-Fu Lee, Inteligencja Sztuczna Rewolucja Prawdziwa. Chiny, USA i przysztość świata (Media Rodzina 2019).

10 Susskind, (n 1) 77. See also: Daryl Pereira, 'How Watson helps lawyers find answers in legal research' (Medium January 2017), <medium.com/@darylp/how-watson-helps-lawyers-find-answers-in-legal-research-672ea028dfb8>, accessed: $20 \mathrm{Jan}-$ uary 2021. 
Virtual assistants will create structured data and documents from unstructured files of any format, extracting thousands of different pieces of information ${ }^{11}$. They will be able to make automated transcription of a person's voice captured on video or in real time, combining this with sentiment analysis ${ }^{12}$. Future robo-assistants will constitute a perceptual AI, and therefore will have the ability to "see", "hear" and understand gestures and sounds received by the "senses"13, they will also be able to place them in the context of a given situation (e.g. how many times during the testimony a witness makes a mistake repeating their version of events or what can be deduced from the contractor's body language during difficult negotiations $)^{14}$.

As a lawyer, AI will also provide direct services to the law firm's clients $^{15}$. The trend on the legal services market is the mass democratisation of specialised services and making them available to people who previously could not afford them ${ }^{16}$. Maintaining revenues at the current level will require lawyers of the future to use AI to contact clients and provide comprehensive service for their cases that can be standardised. It will become common to offer legal aid in the so-called legal advice kiosks where - for a reasonable fee - an interested party will be able to talk to a robo-lawyer about their legal situation, seek advice on the sale or purchase of a property, divorce, writing a will, ask for an analysis of documents or preparation of a contract.

11 Cf., inter alia the PROSAR-AIDA tool, described in the Report of the European Commission: European Commision, 'Study on the use of innovative technologies in the justice field. Final report” (Publication Office European Union 2020) 25.

12 See: Shubham Gupta, 'Sentiment Analysis: Concept, Analysis and Applications' $<$ towardsdatascience.com/sentiment-analysis-concept-analysis-and-applications-6c 94d6f58c17>, accessed: 12 March 2021.

13 Lee, (n 9) $2384 \mathrm{ff}$.

14 Cf. the tool for automated voice transcription and translation, developed by the British company VoiceScript Technologies Ltd., in conjunction with the capabilities of Artificial Intelligence in the analysis of sentiment, content significance, co-reference and correlation, described in the EC Report, (Study on the use) 34 .

15 There are already "prototypes" of robo-lawyers, described, among others, by Igor Bosilkovsky, 'Stanford Grad Who Created The World's First 'Robot Lawyer" Raises \$12 Million In Series A' (Forbes 23 June2020), $<$ www.forbes.com/sites/igorbosilkovski/2020/06/23/stanford-grad-who-created-theworlds-first-robot-lawyer-raises-12-million-in-series-a/?sh=1f6b03d03309> accessed 7 January2021. See also: <https://robotlawyerlisa.com/> accessed 14 January 2021; or <https://robolawyer.weebly.com/>, accessed: 14 January 2021.

16 Susskind, (n 1) $25 \mathrm{ff}$. 
Systems for e-negotiation and e-mediation as well as Online Dispute Resolution (ODR) will also become available to a greater extent, where only AI will be an advisor, mediator or arbitrator ${ }^{17}$. There will also be no obstacles for such an electronic lawyer to appear in court in simple cases, e.g., for payment, when courts will become fully virtual, when they will be more of a "public service" than a place to go for settling the case ${ }^{18}$.

\section{Augmented Intelligence: Centaurs and Cyborgs}

Just as the mythological centaur was half-human, half-horse, the first AI centaurs were half-human, half-AI teams, and played chess much better than the computer itself (they appeared in 1998 when Garry Kasparov led the world's first game of "Centaur Chess" - also called advanced chess or cyborg chess - after his defeat with IBM Deep Blue $)^{19}$.

In the future, in many professions, including the legal one, centaur AI will be the best combination of the machine's ability to remember, verify a huge number of possible scenarios, analyse and detect problems, and human intuition to evaluate or make decisions based on AI performance.

Lawyers of the future, instead of focusing on AI replacing humans ${ }^{20}$, should seek to cooperate with it ${ }^{21}$. The future may bring highly efficient cooperation, not competition ${ }^{22}$. AI will be the best at processing data: millions of numbers, information, images and instantly analysing an unimaginable amount of possible solutions, looking for hidden correlations that elude the human eye and mind, in choosing the best answers. Humans,

17 More on this subject: ibid, $121 \mathrm{ff}$.

18 ibid, $131 \mathrm{ff}$.

19 Nicky Case, 'How To Become A Centaur' (2018) Journal of Design and Science MIT Media Lab <jods.mitpress.mit.edu/pub/issue3-case/release/6>, accessed 14 January 2021; H. G. Escajeda, 'The Vitruvian Lawyer: How to Thrive in an Era of AI and Quantum Technologies' (2020) XXIX Kansas J. of Law \& Pub. Pol'y 421-521, , 463, <https://ssrn.com/abstract=3534683>, accessed 14 January 2021.

20 See forecasts included in the World Economic Forum report "Jobs of Tomorrow. Mapping Opportunity in the New Economy" (January 2020); the report of Deakin University (Australia) and Ford Motor Company Australia Limited, "100 Jobs of the Future" (2019). See also the forecasts presented in the book by Kai-Fu Lee (n 9) $2924 \mathrm{ff}$.

21 William Vorhies, 'An Argument in Favor of Centaur Al' <www.datasciencecent ral.com/profiles/blogs/an-argument-in-favor-of-centaur-ai $>$, accessed: 15 January 2021.

22 Cf. Armour, Parnham, Sako, (n 7). 
on the other hand, are likely to be better at asking questions ${ }^{23}$. It is particularly important in the lawyer's work: questioning well-established patterns, formulating hypotheses, searching for new, non-obvious solutions. In the case of legal AI centaurs, man will pose these "questions" in the form of setting goals and pointing to limitations or exceptions. Meanwhile, AI will search data, analyse dependencies, examine many scenarios and present the most appropriate answers, showing alternative possibilities and their consequences - all in real time, in a conversation with a human partner. This is not all - a lawyer may question AI's answers by asking more complex questions, pointing to additional dependencies that are only noticeable to humans thanks to empathy and intuition ${ }^{24}$. Thus, the AI centaur will be able to work out the best possible solution in a relatively short time.

Augmented Intelligence is not only the one that will be the result of close cooperation between human and AI, as in the case of centaurs. There is increasing trend of improving human intelligence through cyborgisation by embedding implants into the human body or wearing devices that increase the capabilities and computing power of the human brain (the socalled Internet of Body, IoB).The lawyer of the future may be then a cyborg, connected to huge resources of knowledge accumulated in computing clouds, able to read hundreds of information stored in electronic case files using modified eyes or - thanks to a special implant in the brain - analyse possible strategies within seconds during difficult negotiations. Sounds like science fiction? Perhaps. Nevertheless DARPA ${ }^{25}$ (including in the N3: Next-Generation Non-Surgical Neurotechnology Program), Neuralink ${ }^{26}$ and many other organisations conduct advanced research in this direction ${ }^{27}$.

23 Case (n 19).

24 More on the division of roles between humans and AI: Escajeda ( $n$ 19) 464-465; Daniel Araya, 3 Things You Need To Know About Augmented Intelligence, (Forbes 22/01/2019), <forbes.com/sites/danielaraya/2019/01/22/3-thin gs-you-need-to -know-about-augmented-intelligence $/$ ? sh $=4 \mathrm{cda} 84 \mathrm{bd}$ $3 \mathrm{fdc}>$, accessed 10 January 2021. See also: Patryk Zakrzewski, Sztuczna inteligencja rozsadza ramy, $w$ których funkcjonowaliśmy do tej pory - interview with A. Przegalińska <culture.pl/pl/artykul/aleksandra-przegalinska-sztuczna-inteligencja-rozsadza-ramy-w-ktorych-funkcjonowalismy-do-tej-pory-wywiad $>$ accessed: 14 March 2021.

25 Defense Advanced Research Projects Agency - US government agency dealing with the development of military technology.

26 Neuralink Corporation - American neurotechnology company founded, among others by Elon Musk, dealing with the creation of implantable brain-machine interfaces.

27 Magda Gacyk, Zabawy w Boga. Ludzie o magnetycznych palcach (Agora 2020) 1901; Cheyenne Macdonald, Pentagon working to develop technology that would let troops 
Today, no one is surprised by a pacemaker or a bionic limb prosthesis. Soon the effects of implants embedded in a brain that delay the progress of Parkinson's disease or eliminate the negative effects of other neurological diseases will no longer be something unusual ${ }^{28}$. In a dozen years, a lawyer who uses learning opportunities to increase their cognitive abilities, and thus work efficiency, will also become the norm. There are many technological start-ups in the world that intend to accelerate the evolution of bomo sapiens, and transhumanism is also increasingly mentioned in the in the business context ${ }^{29}$.

\section{Artificial Lawyer}

The question remains whether it is possible to create an AI that is humanlike or surpassing human intelligence (Artificial General Intelligence, AGI), and if so, when will it be created. There are as many sceptics among the scientists involved in AI research as there are believers in this "Holy Grail" of AI. Despite the seemingly speculative nature of the AGI, research and development work on its creation is already underway ${ }^{30}$. In his new book,

control machines with their MINDS (Daily Mail 17 July 2018), <dailymail.co.uk/sc iencetech/article-5963803/Pentagon-working-develop-technology-let-troops-con trol-machines-MINDS.html?ns_mchannel=rss\&ito=1490\&ns_campaign=1490> accessed 18 January 2021.

28 Such operations are performed at Stanford University (USA); depression and post-traumatic stress disorder are also treated in the same way. Microsoft is conducting research on brain implants that can restore fitness to people, for example paralyzed, blind or suffering from cerebral palsy. More: Gacyk (n 856) 1936. Also on this topic: I am a human - documentary, dir. E. Gaby, T. Southern, USA 2019.

29 Gacyk (n 856) 1951 The Alcor Foundation in Scottsdale, Arizona conducts research on hibernation and performs (of course for a fee) cryopreservation of the bodies or brains of the deceased in order to revive them in the future in a way that allows the recovery of lost information (and possibly the recovery of bodily damage if the cryopreservation affects the entire body), an example by implementing the "content" of the brain into a computer or android. See: $<$ alcor.org/AboutAlcor/membershipstats.html> accessed 18 January 2021. More on this topic: Mateusz Kulawiński, 'Transhumanizm, cyborgizacja, ulepszanie człowieka' <researchgate.net/publication/334448348_Transhumanizm_cyborgizacja_ulepszanie_czlowieka>, accessed: 13 January 2021.

30 A study by the Global Catastrophic Risk Institute identified 45 research and development projects carried out in 30 countries on 6 continents, many of which are carried out in large corporations and academic institutions. SeeSeth Baum, "A Survey of Artificial General Intelligence Projects for Ethics, Risk, and Policy" (Global Catastrophic Risk Institute Working Paper 17 January 2017) $29<$ https:// 
"Architects of Intelligence" 31 , writer and futurist Martin Ford interviewed twenty-three of the world's most prominent AI scientists, including DeepMind CEO Demis Hassabis, Google AI chief Jeff Dean, and Stanford AI director Fei-Fei Li. In an informal study, they were asked to indicate when the chances of building an AGI would be at least $50 \%$. The most extreme answers were given by: Ray Kurzweil - an American computer scientist, writer, futurologist and promoter of the idea of transhumanism, who suggested that there was a chance to build AGI by 2029 and Rodney Brooks - a member of the Australian Academy of Sciences, a robotics specialist and co-founder of iRobot, which indicated that it would be the year 2200. The remaining votes were split between these two extremes, with an average for the year 2099. In other words, AGI is an undefined future, but it is possible that both the author and the readers of this text will be still alive to see AGI as a lawyer in the law firm of the future. Will such a lawyer of the future have an android form, sensually experiencing the world, entering into social relations, feeling the emotions associated with having a body? Or will it be an extremely advanced computer program, with access to all resources of the Internet and the ability to self-improve, self-replicate and perhaps - being aware (like the Techno Centrum from Dan Simmons' books $\left.{ }^{32}\right)$ ?

It cannot be ruled out that AGI will be created as Distributed Artificial Intelligence through the integration of Multi-Agent Systems or the so-called Swarm Intelligence with Artificial Neural Networks, Deep Learning, including Reinforcement Learning, as well as with other technologies, e.g. Blockchain ${ }^{33}$. Such advanced intelligent systems - capable of exchanging knowledge, experiences, memories, skills and radically modifying their

papers.ssrn.com/sol3/papers.cfm?abstract_id=3070741> accessed 4 August 2021. Some consider OpenAI's GPT-3 as a precursor to AGI. See:.John Thornhill, 'Is AI finally closing in on human intelligence' (Financial Times, 12 November 2020) $<$ https://www. $<$ ft.com/content/512cef1d-233b-4dd8-96a4-0af07bb9ff60 $>$, accessed 13 November 2020.

31 Martin Ford, Architects of Intelligence: The truth about AI from the people building it (Packt Publishing, November 2018).

32 The Hyperion Cantos - a series of science fiction novels by Dan Simmons.

33 Francesco Corea, 'Distributed Artificial Intelligence. A primer on Multi-Agent Systems, Agent-Based Modeling, and Swarm Intelligence' (Medium, March 2019), $<$ francesco-ai.medium.com/distributed-artificial-intelligence-3e3491e0771c $>$, accessed on 14 January 2020. 
own structure - may be more like a swarm of bees than "persons"34. They will also be incomparably more effective in solving problems and finding optimal solutions in a given situation than human lawyers.

Regardless of what form AGI will takes - in order to be able to participate in social relations, including legal ones, and practice the legal profession (as an employee, associate or partner in a future law firm) it must acquire the status of a legal entity. Contrary to many fears and controversies related to this idea, the AGI may become such an "artificial person", without prejudice to what constitutes the content of the legal personality of a person or a corporation. The society of the future should separate the legal personhood from the question of being human or acting by human beings. If we assume that the content of legal personality is the abstract ability to participate in legal relations, then in order to give a specific being the status of a legal person, it is only necessary for the legislator to make such a decision, constructing an appropriate provision allowing it to participate in legal relations, and thus - social life. ${ }^{35}$ It seems that a sufficient condition for the creation of a new category of legal person - an "artificial person" - would be to grant AI some (even very limited) characteristics of the legal person ${ }^{36}$, such as:

1) the right to dispose of specific resources (property) and to make property dispositions, including the conclusion of civil law contracts (with the possibility of limiting the rights in this respect, as in the case of management boards in companies);

2) the right to have legally protected personal rights, such as e.g. name, renown, secrecy of correspondence, as well as other specific for the substrate of a given $\mathrm{AI}$;

3) the right to be protected against loss of integrity, that is, against "switching off", deleting or significantly modifying its memory (these issues should be assessed in court proceedings);

4) the obligation to be subject to third party liability insurance;

5) the right to sue and be sued in civil cases;

34 Cf. Nick. Borstrom, Superinteligencja. Scenariusze, strategie, zagrożenia, (Helion Gliwice 2016) 1998; Aleksander. Chłopecki, Sztuczna inteligencja: szkice prawnicze ifuturologiczne (C. H. Beck 2018), $99 \mathrm{ff}$.

35 More on this topic:Gabriela Bar, 'Robot personhood, czyli po co nam antropocentryczna Sztuczna Inteligencja' in Luigi Lai and Marek Świerczyński (eds.), Prawo Sztucznej Inteligencji (C. H. Beck 2020).

36 Cf Visa A. J. Kurki, 'Why Things Can Hold Rights: Reconceptualizing the Legal Person' in Visa A. J. Kurki, Tomasz Pietrzykowski (eds) Legal Personhood: Animals, Artificial Intelligence and the Unborn (Springer 2017) 85. 
6) the possibility of incurring criminal liability (including being subject to the so-called "kill switch" understood rather as a mechanism for temporary exclusion of AI, instead of its complete annihilation, which is a "penalty" for AI's actions contrary to the law ${ }^{37}$ ).

Having the above-mentioned rights and obligations, a future lawyer who is an AGI could (at least to some extent) be independently responsible for its actions or omissions, which would certainly be a strong argument for "employing" such an "artificial person" in the office or accepting it as a partner.

It is possible that a new legal profession will be created: Artificial Lawyer Its "implementation" will require an entry in an appropriate register, allowing the identification of a given AI. The possibility of practicing this profession should be also dependent on passing the conformity assessment procedure and obtaining a certificate. The EU is already proposing some ideas on future AI regulation, inter alia, in the resolutions of the European Parliament of $20 / 10 / 2020^{38}$. The resolutions provide for the establishment of supervisory authorities responsible for ensuring compliance with the EU regulatory framework for AI development, implementation and application of high-risk AI, robotics and related technologies. Such bodies would be responsible mainly for a coherent EU approach and preventing fragmentation of the single market in the context of AI, conducting AI compliance assessments and awarding the European certification of ethical compliance. Perhaps the next step would be to create the possibility of entering $\mathrm{AI}$ in the register of "artificial (legal) persons". This would require codifying the criteria, the fulfilment of which would make it possible to

37 A temporary switch-off would also be a good solution because it would not raise so many ethical questions about the complete elimination of the conscious mind, and also because it would allow us to investigate the causes of the "malfunction" of AI and perhaps remove the cause of the problem. Moreover, punishing AI in this way would correspond to one of the goals of punishment in the human administration of justice, namely the reform of the individual. More on this topic: Jacob Turner, Robot Rules. Regulating Artificial Intelligence (Springer 2019), 360-361.

38 Cf. European Parliament resolutions of 20/10/2020: on a framework for the ethical aspects of AI, robotics and related technologies (2020/2012 (INL)) and on a civil liability regime for artificial intelligence (2020/2014 (INL)). The newest UE regulation proposal on AI: Proposal for a Regulation of the European Parliament and of the Council laying down harmonised rules on artificial intelligence (Artificial Intelligence Act) and amending certain union legislative acts, Brussels, 21.4.2021 COM(2021) 206 final, <eur-lex.europa.eu/legal-content/EN/TXT/?uri=C ELEX\%3A52021PC0206>, accessed: 4 August 2021. 
acquire the status of such a "person" (it should probably be granted only to the AGI).

This vision of the future may raise a well-founded fear that AGI in the role of a lawyer will be superior to humans in every aspect, and therefore human lawyers will become simply redundant. On the other hand, if empathy, intuition, and relativism are still reserved for people, then for many clients - both in counselling and in court representation this "human factor" will speak in favour of the human being rather than the cool morality of an artificial mind ${ }^{39}$.

\section{Instead of a Summary: Why Changes to Natural Intelligence Are Necessary}

It is a truism to say that the law does not keep up with technology, but it is equally obvious nowadays to say that the human mentality, in particular the attitude to rapidly occurring changes, also "does not keep up" with technological development. The necessary features of a lawyer of the future should therefore be: open mind, creativity, interdisciplinary approach to the profession, acquiring at least basic knowledge in such areas as information technology, machine learning, ethics, philosophy, psychology and neurobiology. Also essential are the ability to adapt to changing conditions and constant learning. Lawyers of the future will need to demonstrate emotional intelligence and a deep understanding of how technology can help achieve their clients' goals. These qualities and skills will certainly be more valuable than formal knowledge ${ }^{40}$.

Regardless of which AI solutions the future lawyers will use, this profession will require digital skills that include knowledge of IT technologies to a level much more advanced than the use of MS Office, as well as the ability to use AI-based LegalTech tools or even to provide legal assistance in cooperation with a highly autonomous AI. Lawyers of the future may not need to be able to programme, but it will undoubtedly be necessary for them to understand the technical aspects of the algorithms and functionality of AI solutions in order to effectively advise clients. In particular, future lawyers will need to know how to assess the strengths and weaknesses of individual solutions, their compliance with the law and ethical princi-

39 Ian McEwan, Maszyny takie jak ja, (Albatros 2019) 3852, 4410 .

40 Anthony E. Davis, 'The Future of Law Firms (and Lawyers) in the Age of Artificial Intelligence' (American Bar Association, 2 October 2020) <https://www.researc hgate.net/publication/340322409_The_Future_of_Law_Firms_and_Lawyers_in_t he_Age_of_Artificial_Intelligence $>$ accessed 4 August 2021. 
ples. ${ }^{41}$ Probably many lawyers will remain only technology consumers, but this may not be enough. Ultimately, it will be necessary to find new roles, adequate to the market needs, with specialisations such as law engineering, legal project management and creating LegalTech tools. ${ }^{42}$.

The way a law firm is managed will also change. Using LegalTech solutions is not without risks, so it will be necessary to provide the so-called assured-AI. The AI systems that the lawyers of the future will use must be designed and constantly verified in terms of reliable operation and cybersecurity. In addition, it is imperative that they will be fully predictable, controllable and at the same time seamlessly integrated with the IT systems used so far. The challenges of choosing tools or systems to ensure such compliance will be one of the important tasks for the managing partners of the law firm of the future ${ }^{43}$.

Ethical and regulatory issues related to risk management in the provision of legal services with the use of AI cannot be overlooked. In the context of compliance with the principles of professional ethics and professional responsibility, one should take into account such issues as algorithmic bias of AI systems, the lack of transparency and explainability of algorithms ${ }^{44}$, carrying out audits of algorithms, the lawyer's responsibility for autonomous decisions AI "employed" in the law firm or the lawyer's failure to apply the recommendations of the AI system and ensuring that the use of AI solutions does not pose a threat to the obligation of profes-

41 Cf. the certificate of ethical compliance proposed in the EP Resolution of October 20, 2020 on a framework for the ethical aspects of artificial intelligence, robotics and related technologies (2020/2012 (INL)).

42 Armour, Parnham, Sako (n 7) 65.

43 In this context, it is important to develop an AI certification system. The American Institute of Electrical and Electronics Engineers Standards Association (IEEE SA) has launched a program called the Ethics Certification Program for Autonomous and Intelligent Systems (ECPAIS), which aims to create specifications for the certification processes of autonomous and intelligent systems (AIS). In the White Paper on Artificial Intelligence, published by the European Commission in February 2020. It was indicated that in the case of high-risk AI systems, compliance assessment should be mandatory, and the assessment system will be based on compliance assessment procedures already known in the EU (e. g. Cybersecurity Act) taking into account the specificity of AI. On the other hand, with regard to AI systems that do not qualify as "high risk", the European Commission proposed the possibility of establishing a voluntary labelling scheme. Cf. the EC proposal of Artificial Intelligence Act.

44 More on this topic: Gabriela Bar, 'Przejrzystość, w tym wyjaśnialność, jako wymóg prawny dla systemów Sztucznej Inteligencji’ (2020) 20 Prawo Nowych Technologii $75 \mathrm{ff}$. 
sional secrecy. Perhaps the right solution to these problems would be to introduce a system of conformity assessment (digital certification) for lawyers ${ }^{45}$.

Without forgetting the risks associated with the use of AI, the lawyer of the future will use it or collaborate with it, creating more for less ${ }^{46}$, providing high-quality services, more accessible, but at the same time tailored to the client's needs ${ }^{47}$.

The future is now. We can see its primroses. There is no doubt that we will not function in the future as a lawyers of the second decade of the 21st century. The lawyer of the future will be an innovator, always seeking, using the achievements of various fields of science, cooperating with experts in the field of the newest technologies, including artificial minds, imagining the impossible and open to continuous development ${ }^{48}$.

45 The project for digital certification of lawyers was submitted to the European Commission by the General Council of Spanish Lawyers (CGAE) as an idea for the future implementation of artificial intelligence or DLT in legal professional organizations. However, according to the information included in the EC Report "Study on the use of innovative technologies ...", this is an idea at a very early stage, with no further progress in its implementation. See (n 11) 176.

46 Susskind (n 1) 16.

47 More on the future of legal services: John Flood and Lachlan Robb, 'Professions and Expertise: How Machine Learning and Blockchain are Redesigning the Landscape of Professional Knowledge and Organisation' (2018) 18-20 Griffith University Law School Research Paper $<$ https://<ssrn.com/abstract=3228950> accessed 19 January 2021; Mark McKamey, 'Legal Technology: Artificial Intelligence and the Future of the Law Practice' (2017) 45 APPEAL 22 Review of Current Law and Law Reform <ssrn.com/abstract=3014408> accessed: 19 January 2021; Michael Legg and Felicity Bell, 'Artificial Intelligence and the Legal Profession: Becoming The AI-Enhanced Lawyer' (2019) 38(2) University of Tasmania Law Review 59, <ssrn.com/abstract=3725949> accessed: 19 January 2021.

48 Escajeda (n 19) 520. 
